\title{
Humidity observations and column simulations for a warm period at the Mars Phoenix lander site : Constraining the adsorptive properties of regolith
}

Savijärvi, Hannu

2020-06

Savijärvi , H , Martinez , G M , Fischer , E , Renno , N O , Tamppari , L K , Zent , A \& Harri , A-M 2020 , ' Humidity observations and column simulations for a warm period at the Mars Phoenix lander site : Constraining the adsorptive properties of regolith ' , Icarus, vol. 343 , 113688 . https://doi.org/10.1016/j.icarus.2020.113688

http://hdl.handle.net/10138/340194

https://doi.org/10.1016/j.icarus.2020.113688

cc_by_nc_nd

acceptedVersion

Downloaded from Helda, University of Helsinki institutional repository.

This is an electronic reprint of the original article.

This reprint may differ from the original in pagination and typographic detail.

Please cite the original version. 


\title{
Humidity observations and column simulations for a warm period at the Mars Phoenix lander site: constraining the adsorptive properties of regolith
}

\author{
H. I. Savijärvi ${ }^{1,2}$, G. M. Martinez ${ }^{3,6}$, E. Fischer ${ }^{3}$, N. O. Renno ${ }^{3}$, L. K. Tamppari ${ }^{4}$, A. Zent ${ }^{5}$, and A.- \\ M. Harri ${ }^{2}$ \\ ${ }^{1}$ Institute for Atmospheric and Earth System Research / Physics, University of Helsinki, Finland \\ ${ }^{2}$ Finnish Meteorological Institute, Helsinki, Finland \\ ${ }^{3}$ Department of Climate and Space Sciences and Engineering, University of Michigan, Ann Arbor, \\ MI, USA \\ ${ }^{4}$ Jet Propulsion Laboratory/California Institute of Technology, Pasadena, California, USA \\ ${ }^{5}$ NASA Ames Research Center, Moffett Field, California, USA \\ ${ }^{6}$ Lunar and Planetary Institute, Universities Space Research Association, Houston, TX, USA
}

revision 2, 17 Jan 2020

\begin{abstract}
Two recalibrated sets of Phoenix (PHX) near-surfaceTECP air humidity measurements were compared with results from adsorptive single column model simulations during a warm clear-sky polar midsummer period, PHX sols 50-60. The model's $2 \mathrm{~m}$ temperatures were close to the observed values. Relative humidity $(\mathrm{RH})$ is very low during the day but at night $\mathrm{RH}$ at $2 \mathrm{~m}$ reaches nearly $100 \%$ by the Zent et al. (2016) recalibration (Z), and $60-70 \%$ by the Fischer et al. (2019) recalibration (F). Model values of $\mathrm{RH} 2 \mathrm{~m}$ are close to $\mathrm{Z}$ and $\mathrm{F}$ at night and to $\mathrm{F}$ during the day. All three imply low water vapor pressures near the surface at night, 0.03-0.05 $\mathrm{Pa}$, with a rapid increase each morning to $0.3-1 \mathrm{~Pa}$ and a decrease in the evening by both $\mathrm{F}$ and the model simulation. The model's daily adsorbed and desorbed water is in balance for regolith porosity of $16 \%$ (instead of $35 \%$ for lower latitudes). The depleted layer of nighttime air moisture extends to only about $200 \mathrm{~m}$ above the surface; hence the model's precipitable water content stays around the observed $\sim 30 \mu \mathrm{m}$ throughout the sol. The model's moisture cycle is not sensitive to tortuosity of the regolith but the in-pore molecular diffusivity should be at least $5 \mathrm{~cm}^{2} / \mathrm{s}$ for fair agreement with the observations. In the adsorption experiments there is no fog and just a hint of ground frost, as observed during this period. Strong night frosts appear if adsorption is made weak or absent in the model.
\end{abstract}

Keywords: Mars, climate; Mars, surface; Meteorology

*Corresponding author at: INAR/Physics, Faculty of Science, 00014 University of Helsinki, Finland

E-mail address: hannu.savijarvi@helsinki.fi

Tel: +358-40-9380858 


\section{Introduction}

The Phoenix spacecraft (PHX) landed on the northern arctic plains of Mars $\left(234^{\circ} \mathrm{E}, 68^{\circ} \mathrm{N}\right)$ in May 2008, prior to the martian northern summer solstice $\left(\mathrm{L}_{\mathrm{s}} 90^{\circ}\right)$. PHX operated for five Earth months, from $\mathrm{L}_{\mathrm{s}} 76.5^{\circ}$ to $148^{\circ}$. Its instrumentation included the Thermal and Electric Conductivity Probe, TECP. The TECP carried a capacitance-based polymer relative humidity (RH) sensor inside its movable probe box on the robotic arm, producing the first in-situ air moisture observations from Mars. The original calibration and initial results, including the RH measurements, are described in Zent et al. (2010). Later, the raw RH counts were recalibrated by Zent et al. (2016), and more recently by Fischer et al. (2019) using the TECP engineering model and the Michigan Mars Environmental Chamber (Fischer et al., 2014). We compare these two recalibrated datasets to single column model simulations in order to study the processes in the diurnal cycle of martian nearsurface moisture. This article focuses on PHX measurements on sols 50-60 ( $\left.\mathrm{L}_{\mathrm{s}} 98^{\circ}-103^{\circ}\right)$, a clearsky warm midsummer period, when frosts, fogs and ice clouds are unlikely to form and there are plenty of raw RH counts available both very near the surface and at 0.48-1.1 m heights.

PHX did detect an underground ice table at $5 \mathrm{~cm}$ below the surface (Smith et al., 2009). Later in the mission, from about sol 70-80 onward, night frosts, fogs and boundary layer (BL) clouds became common (Martinez et al., 2017). With the approaching fall even snowfall from the BL water ice clouds was detected by the Phoenix LIDAR (Whiteway et al., 2009).

Our observational data is described in Sections 2 and 4 and in more detail by Fischer et al. (2019). We use the University of Helsinki/Finnish Meteorological Institute adsorptive subsurfaceatmosphere single column model to simulate the conditions at the PHX landing site. The column model was used previously for Phoenix simulations by Savijärvi and Määttänen (2010, SM10 from now on), but at that time without the inclusion of water adsorption by the regolith. This was added for simulations at the Mars Science Laboratory (MSL) and the Viking lander sites in Savijärvi et al. (2016; 2018; 2019a,b,c). In SM10, the simulation for PHX sol $30\left(\mathrm{~L}_{\mathrm{s}} 90^{\circ}\right)$ reproduced the observed MET mast $2 \mathrm{~m}$ temperatures, telltale slope winds and LIDAR dust profiles relatively well and suggested for the daytime near-surface water vapor partial pressure a value of $0.66 \mathrm{~Pa}$, the TECP first results (Zent et al., 2010) indicating instead a quite high $\sim 1.8 \mathrm{~Pa}$. The SM10 simulation for sol $99\left(\mathrm{~L}_{\mathrm{s}} 122^{\circ}\right)$ did reproduce the LIDAR-observed night fogs and BL clouds quite well. Hence the present atmospheric model part is basically the same as in the well-behaving SM10 model, but it is here equipped with the MSL model scheme for adsorption/desorption in the regolith. This soil scheme is described in detail in Section 3.

The MSL REMS-H humidity device (Harri et al., 2014) is unfortunately not accurate during the warm and dry daytime conditions with very low RH. On the other hand the Michigan PHX TECP/RH recalibration focused specifically on trying to improve the accuracy of the TECP moisture observations during daytime. Here, with that purpose in mind, we hope to gain detailed information of the not so well-known diurnal behavior of near-surface moisture on Mars (Montmessin et al., 2017), especially during the morning, daytime and evening, by interpreting the recalibrated TECP observations with the help of model simulations (Section 4) and sensitivity experiments (Section 5). Our conclusions are given in Section 6.

\section{TECP calibrations}

The original pre-flight calibration of the TECP's relative humidity sensor was performed at the University of Washington (Zent et al., 2009), covering temperatures between 208 and $303 \mathrm{~K}$ and frost point temperatures between 194 and $263 \mathrm{~K}$, resulting in calibrated relative humidity values between $\sim 0$ and $55 \%$. Then, after finding only a partial overlap between in-situ measurements and 
101 calibration points, a new post-flight calibration was performed by Zent et al. (2016). They added three low-temperature data points obtained during the mission, when the atmosphere is

independently known to be saturated, and changed the calibration function to frost point $\left(\mathrm{T}_{\mathrm{f}}\right)$ instead of RH. This calibration resulted in water vapor pressure values in the range of $\sim 0.004-0.4 \mathrm{~Pa}$ throughout the mission.

More recently, the TECP RH sensor data was recalibrated at the University of Michigan by Fischer et al. (2019), to further improve the measurement accuracy, specifically during the hightemperature/low-humidity and low-temperature/high-humidity extremes observed at the Phoenix landing site. While the low-temperature range remained rather similar to the previous calibration by Zent et al. (2016), using in-situ measurements at known saturated conditions, the high-temperature range of the calibration was improved by using in-situ temperature measurements and new laboratory measurements, while assuming a maximum water vapor pressure based on independent orbital measurements. This recalibration used a spare engineering model of the TECP inside an environmental chamber (the Michigan Mars Environmental Chamber) to cover the entire range of temperature, pressure and humidity conditions encountered by the TECP flight unit on Mars for generating a new calibration function, while taking into account any differences between the flight and spare models. This calibration resulted in water vapor pressure values in the range of $\sim 0.005-$ $1.4 \mathrm{~Pa}$, similar to the previous calibration at nighttime, but showing considerably larger values at daytime. These new daytime values match ground-based estimates made by the Surface Stereo Imager (SSI) instrument of Phoenix, as well as orbital estimates by CRISM. They are an order of magnitude larger than those suggested for the dry equatorial MSL landing site, as expected for the high latitude of Phoenix just after the sublimation of the polar water ice cap.

\section{The column model}

The atmospheric part of the column model has been described in SM10, so only a brief account is given here; the adsorptive subsurface scheme for porous regolith is described below in more detail. The air column with constant geostrophic wind $\mathrm{V}_{\mathrm{g}}$ is assumed hydrostatic without advections. Parameterizations include turbulence (a Monin-Obukhov surface layer scheme with a mixing length approach aloft), short- and longwave radiative effects for $\mathrm{CO}_{2}, \mathrm{H}_{2} \mathrm{O}$, dust, clouds and fogs, and radiatively interactive moist physics. The diurnally varying surface energy balance determines surface temperatures. Water vapor mass mixing ratio $\mathrm{q}$ is the moisture predictand. Supersaturation $\left(q>q_{s a t}(p, T)\right)$ leads to accumulation of ice clouds and fogs; subsaturation to sublimation of them, with latent heat effects included both ways. There are 29 air grid points at heights of $0.3,0.8,2,5$, $10 \mathrm{~m}$... from the surface; the top is at $50 \mathrm{~km}$. Time step is $20 \mathrm{~s}$. For the Phoenix site the soil thermal inertia is $150 \mathrm{SI}$ units, albedo 0.18 and surface roughness length $\mathrm{z}_{\mathrm{o}} 0.01 \mathrm{~m}$, producing for $\mathrm{V}_{\mathrm{g}}$ of $10 \mathrm{~m} / \mathrm{s}$ near-surface diurnal winds of $\sim 4-6 \mathrm{~m} / \mathrm{s}$, as observed by the Phoenix telltale (Martinez et al., 2017; SM10). Dust is assumed to be well-mixed.

In the soil vertical diffusion of soil temperature $T_{s}$ and pore air water vapor (mixing ratio $\mathrm{q}_{\mathrm{s}}$ ) is solved implicitly at eight depths, which are optimized for accurate prediction of $\mathrm{T}_{\mathrm{s}}$, as discussed in SM10. The depths are $0,0.25,0.5,2,3.8,7.5, . ., 35 \mathrm{~cm}$ for the Phoenix site. At any time the moisture flux from the soil surface (positive upward) must equal the flux to the lowest air layer:

$$
-\left.D_{e} \frac{\partial \rho_{s} q_{s}}{\partial z}\right|_{z=0}=f \rho_{a} C_{h} V_{a}\left(q_{s}(0)-q_{a}\right)
$$

where $\rho_{\alpha}, \mathrm{V}_{\mathrm{a}}$ and $\mathrm{q}_{\mathrm{a}}$ are the density, wind speed and mixing ratio in the lowest air point, $\mathrm{q}_{\mathrm{s}}(0)$ is the mixing ratio of pore air at the surface, $\mathrm{C}_{\mathrm{h}}$ the stability- and roughness-dependent scalar transfer coefficient (given by the model's surface layer scheme described in SM10 and in Savijärvi and 
152

153

154

155

156

157

158

159

160

161

162

163

164

165

166

167

168

169

170

171

172

173

174

175

176

177

178

179

180

181

182

183

184

185

186

187

188

189

190

191

192

193

194

195

196

197

198

199

200

201

Kauhanen, 2008), $f$ porosity (the fractional air volume in the soil) and $D_{e}$ the effective diffusivity of porous soil. Surface- $q_{s}$ can be solved from the finite difference version of (1) at each time step. Following Zent et al. (1993) non-ice water is assumed to exist in the soil, both as vapor in the pore space (with density $w=q_{s} \rho_{s}$ ) and as adsorbate $a(w, T)$ on the regolith grain surfaces. Vapor is able to diffuse vertically within the pore space. Thus, in a unit volume of porous soil

$$
\frac{\partial}{\partial t}(f w+a(w, T))=-\frac{\partial}{\partial z}\left(-D_{e} \frac{\partial w}{\partial z}\right)
$$

Assuming that $f$ is constant and air temperature in the pores adopts $T_{s}(\mathrm{z})$ but its small density change effects are negligible, this leads at each depth to

$$
\frac{\partial q_{s}}{\partial t}=\frac{1}{f c} \frac{\partial}{\partial z}\left(D_{e} \frac{\partial q_{s}}{\partial z}\right)-\frac{1}{\rho_{s} f c} \frac{\partial a}{\partial T_{s}} \frac{\partial T_{s}}{\partial t}
$$

where $\rho_{\mathrm{s}}$ is pore air density $\left(=p / R T_{s}\right)$ and $c=1+(1 / f) \partial a / \partial w$. In practice, at each time step after the update of $\mathrm{T}_{\mathrm{s}}$ (and of $c, D_{e}$ ) at each depth, $q_{s}$ is first updated by the fast and strong last term of (2), then $q_{s}(0)$ is updated from (1) and used as the top boundary condition for solving the slower diffusion part of (2). Finally conditions for super/subsaturation are checked at each depth and the amounts of surface frost and pore ice $q_{i}(z)$ are updated accordingly. The Jakosky et al. (1997) adsorption isotherm (J97) is mainly used for $a(w, T)$ but other formulations or tabulations can easily be adopted, since $\partial a / \partial w$ and $\partial a / \partial T$ are estimated by finite differencing. If adsorption is set to 0 (no adsorption), only the unscaled ( $\mathrm{c}=1$ ) diffusion part of (2) operates in the regolith. If $f \rightarrow 0$, as for solid rock, there are in the limit no pores and hence no surface interactions of moisture, except for possibly frost.

The effective diffusivity $D_{\mathrm{e}}$ of porous regolith is formally $D_{e}=\left(f / \tau_{\mathrm{s}}\right) \cdot D$. Here $D=D(p, T)$ is the molecular Fick/Knudsen diffusivity of water vapor in $\mathrm{CO}_{2}$ gas, $f$ (porosity) the cross sectional area available for free-path molecular diffusion, and $\tau_{\mathrm{s}}$ the tortuosity, which describes the relative path increase due to the winding gas routes and dead ends in the porous soil, best determined by measurements (Montmessin et al., 2017). Hudson et al. (2007) have made laboratory measurements of $D_{e}$ for Mars-like conditions, using the purely Fickian formulation for $D$ from Wallace and Sagan (1979) (which we will also adopt):

$$
D=0.1654 \cdot\left(p_{o} / p\right)\left(T / T_{o}\right)^{3 / 2} \mathrm{~cm}^{2} / \mathrm{s}
$$

where $p_{o}=1013.25 \mathrm{mb}$ and $T_{o}=273.15 \mathrm{~K}$. For JSC-1 volcanic ash Hudson et al. (2007) report $f \sim$ $58 \%, D_{e} \sim 5.4 \mathrm{~cm}^{2} / \mathrm{s}$, so $\tau_{\mathrm{s}} \sim 2.6$ and $1 / \tau_{\mathrm{s}} \sim 38 \%$. For their proxy for aeolian regolith on Mars (glass beads in a $40-70 \mu \mathrm{m}$ size range $(f \sim 44 \%)$ at $6 \mathrm{mb}, 260 \mathrm{~K}$ of $\left.\mathrm{CO}_{2}\right)$ Hudson et al. obtained $D_{e} \sim 4.5$ $\mathrm{cm}^{2} / \mathrm{s}$, so $\tau_{\mathrm{s}} \sim 2.4$ in reference to (3). Hence $1 / \tau_{\mathrm{s}}$ is $42 \%$, i.e. very close to the $f$ of $44 \%$.

If $1 / \tau_{\mathrm{s}}$ equals $f$, the famous 'Buckingham law' $D_{e} \sim f^{2} D$ results. This was adopted in Savijärvi et al. (2016), inspired by calculations of Meslin et al. (2010). On the other hand some laboratory experiments (e.g. Sizemore and Mellon, 2008) suggest $\tau_{\mathrm{s}} \sim f^{-1 / 2}$, so then $\mathrm{D}_{\mathrm{e}} \sim f \sqrt{f} D$. The Phoenix data may now provide an opportunity to test these two suggestions for $D_{e}(f)$ against real martian atmospheric observations, and also the sensitivity to using various constant values for $D$ and $D_{e}$. Previously adopted constant values include e.g. $D$ of $1 \mathrm{~cm}^{2} / \mathrm{s}$ (Zent et al., 1993; Schorghofer and Aharonson, 2005, Savijärvi et al., 2016), and $D$ of $5 \mathrm{~cm}^{2} / \mathrm{s}$ (Savijärvi et al., 2018; 2019a; 2019b). During midsummer conditions at Phoenix ( $p \sim 8 \mathrm{mb}, T_{g} \sim 191-260 \mathrm{~K}$, Fig. 1 ), the $D\left(p, T_{g}\right)$-range of (3) is $12-20 \mathrm{~cm}^{2} / \mathrm{s}$.

The apparent porosity $f$ around Phoenix is not well known. We define it, as in our previous 
experiments, by finding a value which produces the best match with the diurnal near-surface moisture observations while simultaneously preserving the column water contents from sol to sol at their orbit- and SSI-observed mean daytime values. The soil might experience a net loss of water during this season and advection could carry away the gain to the atmosphere but these effects are probably small in the timeframe of a few sols. We thus assume a fully reversible daily cycle of adsorption and desorption, the observations shown appearing to be approximately consistent with that.

\section{Results for clear skies: Phoenix sols 50-60}

Before sol 50 there are only a few daytime TECP RH observations and almost no nighttime observations. On the other hand from about sol 70-80 onward there were regular frosts, fogs and boundary layer clouds at the Phoenix site (Martinez et al., 2017). We hence present here results and comparisons for sols 50-60, when there were enough RH observations to define the full diurnal cycle of near-surface moisture without major complicating condensation effects, and the solar height angles and optical depths did not vary too much during the short 10 -sol stretch. This midsummer $\mathrm{L}_{\mathrm{s}} 98^{\circ}-103^{\circ}$ period represents the warmest time at Phoenix (Davy et al., 2010), the sky being fairly clear all the time. The available first-per-each-hour TECP RH data from the Zent et al. $(2016, \mathrm{Z})$ and the Fischer et al. $(2019, \mathrm{~F})$ recalibrations for this period are applied. During sols 5455 the TECP needles were within the surface (Zent et al., 2010), so these RH measurements are taken from very near the surface, at about $3 \mathrm{~cm}$ height. For the other sols the RH measurements refer to various heights $48-111 \mathrm{~cm}$ above the surface (Zent et al., 2010). The sol 54-55 values for water vapor pressure $e$ are respectively called 'surface- $e$ ' in what follows; the others being 'air- $e$ '.

The RH sensor was located inside the TECP box next to the board temperature sensor $T_{b}$, which measures air temperature within the box. Solar heating of the box and heating due to the board electronics increase $\mathrm{T}_{\mathrm{b}}$ above ambient air temperature, thereby decreasing the measured internal $\mathrm{RH}$ below ambient RH (and also preventing harmful internal frost effects). The measured $\mathrm{RH}$ at $\mathrm{T}_{\mathrm{b}}$ is converted in the recalibrations to the frost point temperature $T_{f}$, from which the water vapor partial pressure $e$ is obtained. Since $\mathrm{RH}=e / e_{\text {sat }}(T)$, ambient $\mathrm{RH}$ at $2 \mathrm{~m}$ height can then be evaluated using for $e_{\text {sat }}$ the observed $2 \mathrm{~m}$ temperature from the MET mast and assuming that $e$ is constant with height. This assumption will be commented on later. For $e_{s a t}(T)$ we use the formulation of Savijärvi et al. (2016), which is extremely accurate with regard to the reference values of Murphy and Koop (2005) in the temperature range 190-273 K relevant here.

The column simulations for average conditions during sols $50-60$ were made by having $\mathrm{L}_{\mathrm{s}}$ of $101^{\circ}$ (sol 55) and initially setting T to $220 \mathrm{~K}$ at the surface with lapse of $1.3 \mathrm{~K} / \mathrm{km}$ and the water vapor mass mixing ratio q to $200 \mathrm{ppmm}$, with linear decrease to 0 at $35 \mathrm{~km}$. The q-profile is based on GCM results for the season and latitude (Navarro et al., 2014; Montmessin et al., 2017). It produces an initial column precipitable water content (PWC) of $31.7 \mu \mathrm{m}$, near the observed average PWC of $\sim 30 \mu \mathrm{m}$ by CRISM and PHX/SSI for PHX sols 50-60 (Tamppari et al., 2010; Zent et al., 2016). Soil pore mixing ratios $\mathrm{q}_{\mathrm{s}}(\mathrm{z})$ are initially set to the boundary layer mean $(0-4 \mathrm{~km})$ of air-q(z), $188 \mathrm{ppmm}$. Surface pressure is the observed $800 \mathrm{~Pa}$ and the total visible optical depth $\tau$ is 0.33 (dust 0.3 plus a seasonal high icecloud, 0.03).Results are shown from the third model sol, when the model is repeating its diurnal cycle of winds, temperatures and moistures, conserving $\mathrm{PWC}$ at the observed $\sim 30 \mu \mathrm{m}$ from sol to sol. The ground porosity $f=0.16$, the Buckingham law $D_{e}=f^{2} D\left(p, T_{s}(z)\right)$ and the J97 adsorption isotherm are used in the reference simulation described below. Sensitivity tests will be shown in Section 5. Our initial q-profile suggests a volume mixing ratio $(v m r=q / 0.41)$ of about $488 \mathrm{ppmv}$, and water vapor pressure $(e=v m r p)$ of about $0.39 \mathrm{~Pa}$, at the surface. The main parameters of the reference simulation are shown in Table 1. 
Table 1. Main parameters used in the UH/FMI SCM reference simulation for Phoenix at $\mathrm{L}_{\mathrm{s}} 101^{\circ}$ (PHX sol 55).

\begin{tabular}{|l|l|}
\hline Parameter & Value \\
\hline Soil thermal inertia I & $150 \mathrm{~J} \mathrm{~m}^{-2} \mathrm{~K}^{-1} \mathrm{~s}^{-1 / 2}$ \\
\hline Surface albedo $\alpha$ & 0.18 \\
\hline Surface emissivity $\varepsilon_{\mathrm{g}}$ & 0.97 \\
\hline Surface roughness length $\mathrm{z}_{\mathrm{o}}$ & $0.01 \mathrm{~m}$ \\
\hline Geostrophic wind speed $\mathrm{V}_{\mathrm{g}}$ & $10 \mathrm{~ms}^{-1}$ \\
\hline Surface pressure $\mathrm{p}$ & $800 \mathrm{~Pa}$ \\
\hline Dust visible optical depth $\tau$ & 0.30 \\
\hline Initial PWC & $31.7 \mu \mathrm{m}$ \\
\hline Ground porosity $f$ & $16 \%$ \\
\hline Molecular diffusivity $o f \mathrm{H}_{2} \mathrm{O}$ in $\mathrm{CO}_{2} D(p, T)$ & Equation 3 \\
\hline Adsorption isotherm $a(w, T)$ & Jakosky et al. $(1997)$ \\
\hline Ground tortuosity $\tau_{\mathrm{s}}$ & $6.25(=1 / f)$ \\
\hline
\end{tabular}

Fig. 1 presents the sol 50-60 TECP observations of $\mathrm{T}_{\mathrm{b}}$ and the two recalibrated ( $\mathrm{F}$ and $\mathrm{Z}$ ) frost point temperatures $\mathrm{T}_{\mathrm{f}}$, together with the simultaneous MET T2m observations and the model's T2m and ground temperature $T_{g}$. One may note that $T_{b}$ is in general higher than MET T2m, as expected. $T_{b}$ displays lower values at around 1500 LTST (local true solar time), due to temporary shadowing of the TECP box from sun by the lander body. The model's T2m curve is quite close to the observed $\mathrm{T} 2 \mathrm{~m}$. During the day the Fischer et al. (2019)-recalibrated $\mathrm{T}_{\mathrm{f}}$ is clearly higher than that from the Zent et al. (2016) recalibration. During the night the two frost points are instead fairly similar. They are below T2m all the time, so fog is unlikely. From midnight to 0100 LTST they tend to be slightly above the model-predicted surface temperature $T_{g}$. Hence light frost might temporarily appear at the (model) ground.

Fig. 2 displays $\mathrm{RH}=e / e_{\text {sat }}(\mathrm{T})$ at $2 \mathrm{~m}$ height; $e$ as evaluated from the two recalibrations and $e_{\text {sat }}$ taken at the MET T2m. RH2m is high at night for both recalibrations, almost hitting $100 \%$ by the Zent recalibration $(\mathrm{RH} 2 \mathrm{~m}, \mathrm{Z})$ and by the model, whereas the max $\mathrm{RH} 2 \mathrm{~m}, \mathrm{~F}$-values are around $60 \%$. During the warm afternoons RH is quite low, especially by the Zent recalibration. Fig. 2 suggests that during the night the model's RH2m stays closer to the Zent recalibration but during the day the model result is much closer to the $\mathrm{F}$ recalibration.

Ice fogs were first detected at Phoenix by SSI at sol 61 (Moores et al., 2011), and became common later on. Zent et al. (2016) display $\mathrm{T}_{\mathrm{f}}$ exceeding the MET T2m around 0100 LTST on sol 55, when the TECP was at the cold surface. Hence RH $2 \mathrm{~m}$ by Z being slightly below $100 \%$ at $2 \mathrm{~m}$ height at this time in Fig. 2 appears realistic and light frost was likely at the cold ground. The reference simulation indicates no fog but very light ground frost just around 0200 LTST.

The water vapor partial pressure $e$ is shown in Figure 3. Here the Fischer et al. surface-e (at $\sim 3 \mathrm{~cm}$ height, sols 54-55, sfc-F) are the filled squares, and $e$ from sols 50-53, 56-59 (air-F, at 48-111 cm heights) are open squares, whereas all $e$ from $\mathrm{Z}$ are triangles for clarity. Model curves of $e$ are from the surface (dash-dotted), and from air at $2 \mathrm{~m}$ height (solid). During the night the observed $e$-values of surface-F are quite small, down to 0.04-0.06 $\mathrm{Pa}$ (estimated error for these low values being $\pm 0.005 \mathrm{~Pa}(17 \%)$ by Fischer et al., 2019). They increase rapidly after 0300 LTST, presumably indicating desorption of water from the sun-heated regolith. The model's surface $e$-curve (dashdots) matches the surface-F values very well in the morning, air-F of $e$ (open squares) becoming 0.3-0.5 $\mathrm{Pa}$ in the afternoon with some scatter, but close to the model-predicted $e$ at $2 \mathrm{~m}$ (solid line). 
Interestingly, the midday $e$-values of surface-F are quite high, up to $1 \mathrm{~Pa}$, indicating relatively high desorption rates and consequently quite strong midday vertical gradients in $e$ above the hot ground. The estimated midday error of the F-calibrated $e$ is $\pm 0.3 \mathrm{~Pa}(26 \%)$. The model curves indicate much smaller midday vertical gradient in $e$ (high gradient might call for very high model vertical resolution near the ground). The Zent recalibration displays instead quite low daytime values, $e<$ $0.1 \mathrm{~Pa}$.

From about 1800 LTST onward, when $\mathrm{T}_{\mathrm{g}}$ and $\mathrm{T} 2 \mathrm{~m}$ decrease rapidly and the near-surface air becomes statically stable $\left(\mathrm{T}_{\mathrm{g}}<\mathrm{T} 2 \mathrm{~m}\right.$, Fig. 1$)$, the $\mathrm{F}$ values of surface-e drop rapidly in Fig. 3, probably due to downward diffusion and adsorption onto the cooling regolith grains as in the model. Night observations of $e$ are all from very near the surface. The model's surface- $e$ matches these well, whereas its values at $2 \mathrm{~m}$ are higher, indicating a nocturnal surface inversion in humidity due to adsorption. Hence the assumption of vertically constant well-mixed absolute humidity appears to be slightly invalid above a strongly desorbing and strongly adsorbing regolith.

This is further demonstrated in Fig. 4, which displays the model's initially linear q-profile from $0.01 \mathrm{~m}\left(=z_{0}\right)$ to $20 \mathrm{~km}$, and the resulting model profiles at 0200, 0800, 1200 and 2000 LTST. Note the logarithmic scale, which emphasizes the near-surface behavior. Strong midday desorption and convection mixes moisture nearly evenly to about $4 \mathrm{~km}$ height by the afternoon (just as dust in the PHX/LIDAR-observed profiles; Whiteway et al., 2009). Downward diffusion and adsorption to the regolith then depletes moisture during the evening and night in a shallow air layer below about 200 $\mathrm{m}$ by Fig. 4. Desorption is then activated by the morning sunshine (Fig. 3), and strong convection quickly mixes the desorbed moisture nearly evenly into the growing convective boundary layer. The CBL reaches to about $500 \mathrm{~m}$ by 0800 LTST, to about $2 \mathrm{~km}$ by midday, and to $4 \mathrm{~km}$ during the afternoon, by Fig. 4. Because the diurnally depleted layer of moisture is quite low $(<200 \mathrm{~m})$, PWC does not vary diurnally a lot due to adsorption. Its daily minimum is $29.74 \mu \mathrm{m}$ at 0900 LTST and maximum $30.03 \mu \mathrm{m}$ at 1600 LTST in the reference simulation; a diurnal variation of just $1 \%$.

No fog and just a hint of frost around 0200 LTST appears in the reference simulation, so the diurnal variation of $e$ is solely due to the vertical diffusion-desorption-adsorption cycle. The good match of the model with the F recalibration suggests that the model is presumably realistic but this also suggests that the F recalibration was worthwhile and realistic. The apparent strong diurnal variation of $e$ is most probably due to adsorption. The Zent 2016 recalibration is also quite good during the night hours but during daytime it does not coincide with the F recalibration and the model in the light of Figs. 1-3.

\section{Sensitivity tests and discussion of the depletion mechanism and soil physics}

Here sensitivity tests are made concerning various model parameters and weather conditions at Phoenix, changing one property at a time, everything else remaining the same as in the above reference simulation defined in Table 1. The recalibrated values of $e$ (from Fig. 3 but now in linear scale) are displayed in Figs. 5-7, together with $e$ at $2 \mathrm{~m}$ height from various model experiments. The model's surface-e (not shown for clarity) is in all cases about $0.1 \mathrm{~Pa}$ higher than $e$ at $2 \mathrm{~m}$ during the midday hours and about $0.04 \mathrm{~Pa}$ lower than $e 2 m$ during the night hours, as displayed for the reference simulation in Fig. 3 (the solid and dash-dotted lines).

The model's air and soil temperatures (Fig. 1) remain unchanged in the experiments as water phase changes are not involved in the adsorption-desorption cycle and the frost amounts remain insignificant (depth $<0.1 \mathrm{pr} \mu \mathrm{m}$ ) in all experiments with adsorption switched on. The model results are not sensitive to variations in $C_{h}$ and wind speed as long as the surface winds are higher than 
about $1 \mathrm{~m} / \mathrm{s}$ (here they are 4-6 m/s), as shown in Savijärvi et al. (2016).

When first varying the porosity of soil around Phoenix, the best model match with the diurnal TECP observations is obtained for $f$ of $16 \%$ (Fig. 5). This is further supported by the fact that PWC then remains at around $30 \mu \mathrm{m}$ from sol to sol as observed, whereas with $f$ of $5 \%$ PWC rapidly decreases, and with $f$ of $30-35 \%$ (the best values for Curiosity and the two Viking landers), PWC increases from sol to sol during the integration. The daytime values of $e$ are the most sensitive to $f$ by Fig. 5 . Zent et al. (2010) estimated $f$ of $44-50 \%$ for Phoenix, but this might represent just the spot around the TECP needles, whereas the model- $f$, like its thermal inertia and albedo, represents apparent average conditions of the soil all around the lander. The small model-indicated porosity at Phoenix (16\%) compared to those for the loose-sand-like Curiosity and Viking sites (30-35\%) is consistent with the crusted and cloddy top regolith around Phoenix (Smith et al., 2009), where the soil grains may have been cementated by carbonates and other salts in the presence of water, as suggested by Boynton et al. (2009).

Fig. 5 also presents a simulation with tortuosity $\tau_{\mathrm{s}}$ set to $2.5\left(=f^{-1 / 2}\right)$ instead of $6.25\left(=f^{-1}\right)$ of the reference simulation. This only makes a tiny difference in Fig. 5, so the exact value of $\tau_{\mathrm{s}}$ is of less importance for modelling of adsorption/desorption, as long as $\tau_{\mathrm{s}}$ is made somehow inversely proportional to $f$. Such an inverse proportionality guarantees the quite natural condition of no moisture flux due to adsorption over solid ground (no pores, $f \sim 0$ ), because $f$ itself cancels out in (1) after substituting $D_{e}=\left(f / \tau_{\mathrm{s}}\right) \cdot D$.

The adsorption isotherm J97 was also varied. Simulations with the Fanale and Cannon (1971) isotherm (FC71) were not in balance for realistic porosities; instead PWC always increased rapidly from sol to sol due to excessive daytime desorption, similarly to Steele et al. (2017) and Savijärvi et al. (2016) for Curiosity, and to Savijärvi et al. (2018) for the Viking landers. In contrast, use of the Zent and Quinn (1997) isotherm (ZQ97) produced air moisture results for Phoenix, as well as for the Viking landers and Curiosity, which agree with the available observations and are nearly identical to those obtained by J97. Thus the J97 and ZQ97 adsorption isotherms appear generally applicable for regolith on Mars, whereas FC71 is less valid.

In Fig. 6 constant values for the molecular diffusivity $D$ are tested. $D$ of $1 \mathrm{~cm}^{2} / \mathrm{s}$ (dotted line) appears to produce a weak soil moisture flux, hence it displays weaker evening depletion than the F-observations and the reference simulation. This leads to frost deposition taking place from 2200 LTST onward. At 0500 LTST all frost has sublimated away and thereafter weak desorption with upward diffusion prevails. The $D=5 \mathrm{~cm}^{2} / \mathrm{s}$ simulation (dash-dotted) is instead quite close to the reference case in Fig. 6, but light frost still appears in it between midnight and 0400 LTST.

Fig. 6 displays furthermore a simulation, where adsorption is set to 0 but soil diffusion does remain active in the porous regolith. This no-adsorption case $(\mathrm{a}=0$, dashed) shows only very weak evening moisture depletion at $2 \mathrm{~m}$, due here only to the unscaled downward diffusion in the soil pores. After 2200 LTST heavy frost formation hence takes over in the now relatively moist surface layer. Frost depth reaches $0.74 \mathrm{pr} \mu \mathrm{m}(2.5 \%$ of PWC) by 0400 LTST in this simulation but frost sublimates rapidly away in the clear-sky morning sun (there is no fog), hence making a weak peak to model$e 2 \mathrm{~m}$ at 0600 LTST in Fig. 6 . There is also a hint of pore ice within the regolith in this case during the coldest morning hours, unlike in all the other simulations.

The available water amount is varied in Fig. 7, from a low PWC of $25 \mu \mathrm{m}$ to a high PWC of $35 \mu \mathrm{m}$ (vs. $30 \mu \mathrm{m}$ in the reference simulation). Also these low and high PWC values are conserved fairly well from sol to sol for $f$ of $16 \%$ (but not for the other other $f$, with spreads then similar to those in Fig. 5), which gives more support to the $16 \%$ estimate for $f$. The rather scattered daytime 
observations of air-F (open squares) match perhaps best with the reference simulation according to Fig. 7, the model's $e 2 \mathrm{~m}$ curves from the $25 \mu \mathrm{m}$ simulation staying on the low side, and those from the $35 \mu \mathrm{m}$ simulation on the high side, of the daytime air-F values. Nighttime vapor pressure values are less sensitive to the assumed PWC.

Fig. 7 furthermore displays the case of $f$ approaching 0 , i.e. solid rock ground. In this case there is no surface flux of moisture during the day (no interaction, dashed line). Hence $e 2 \mathrm{~m}$ remains constant at $0.38 \mathrm{~Pa}$ late to the evening, until the surface frost point is reached, with heavy frost thereafter deposited onto the ground. This depletes air moisture very rapidly from 2100 LTST onward in Fig. 7 (as in SM10 for sol 30 with no adsorption in that model version). The frost depth reaches in this case $1.01 \mathrm{pr} \mu \mathrm{m}$ by 0400 LTST ( $3.3 \%$ of PWC), sublimating thereafter. As there is here more frost than in the no-adsorption case $(0.74 \mathrm{pr} \mu \mathrm{m})$ of Fig. 6 , the respective sublimation peak in $e 2 \mathrm{~m}$ is also stronger at $0600 \mathrm{LTST}$.

In all the above experiments RH at $2 \mathrm{~m}$ stays below $120 \%$, which is the critical value for initiation of fog in our model. Therefore no fog occurs at $2 \mathrm{~m}$ in the above simulations, as either adsorption or frost, or both, manage to remove enough moisture from the air in the evening to prevent fog. However, if ground frost and/or adsorption is artificially shortcut, thick fog is formed near the surface every night in such experiments.

Finally, some in-soil temperatures $\mathrm{T}_{\mathrm{s}}$, water vapor densities $f w=f q_{s} \rho_{s}$ and adsorbed water amounts $a\left(w, T_{s}\right)$ per unit volume of regolith are demonstrated in Table 2 from the reference simulation with the J97 adsorption isotherm. Values are shown down to $3.8 \mathrm{~cm}$ depth at 0200, 0800, 1400 and 2000 LTST (below $5 \mathrm{~cm}$ there is ice table but in the timeframe of three sols this has little impact on the daily adsorption and desorption, which takes place essentially in the top $1 \mathrm{~cm}$ of soil, as shown in Table 2). The vapor density mainly follows the damped and lagged soil diurnal temperature wave in the ground. Adsorbed surface water amounts range from $0.98 \mathrm{~kg} \mathrm{~m}^{-3}$ at 1400 LTST to $1.63 \mathrm{~kg} \mathrm{~m}^{-3}$ at 0200 LTST (assuming regolith density of $1000 \mathrm{~kg} \mathrm{~m}^{-3}$ ), settling to about $1.28 \mathrm{~kg} \mathrm{~m}^{-3}$ at $3.8 \mathrm{~cm}$ depth. This is about three times the diurnally adsorbed water at MSL for $\mathrm{L}_{\mathrm{s}} 189^{\circ}$ in Steele et al. (2017, their fig. 10 for the J97 isotherm), but then again PWC at Phoenix (30 $\mu \mathrm{m})$ is about threefold that at MSL (11 $\mu \mathrm{m}$ for $\mathrm{L}_{\mathrm{s}} 189^{\circ}$, McConnochie et al., 2018).

Table 2. Temperatures $\mathrm{T}_{\mathrm{s}}$, water vapor densities $f w$ and adsorbed water amounts at five depths $\mathrm{z}(0$ $3.8 \mathrm{~cm}$ ) in the regolith according to the Phoenix sol 55 reference simulation (Table 1) with the J97 adsorption isotherm.

\begin{tabular}{|l|r|l|l|l|l|l|l|l|l|l|l|l|l|l|l|}
\hline & \multicolumn{4}{|c|}{$\mathrm{T}_{\mathrm{s}}(\mathrm{K})$} & \multicolumn{4}{c|}{$f w\left(\mathrm{mg} \mathrm{m}^{-3}\right)$} & \multicolumn{4}{c|}{ adsorbed water $\left(\mathrm{kg} \mathrm{m}^{-3}\right)$} \\
\hline $\mathrm{z}(\mathrm{cm})$ & 0 & 0.25 & 0.50 & 2.0 & 3.8 & 0 & 0.25 & 0.50 & 2.0 & 3.8 & 0 & 0.25 & 0.50 & 2.0 & 3.8 \\
\hline $0200 \mathrm{~h}$ & 191 & 193 & 195 & 207 & 216 & 0.4 & 0.3 & 0.3 & 0.7 & 1.1 & 1.63 & 1.34 & 1.27 & 1.34 & 1.28 \\
\hline $0800 \mathrm{~h}$ & 236 & 232 & 228 & 216 & 212 & 2.1 & 2.1 & 1.7 & 1.1 & 0.9 & 1.15 & 1.22 & 1.20 & 1.32 & 1.29 \\
\hline $1400 \mathrm{~h}$ & 260 & 257 & 255 & 240 & 226 & 3.8 & 4.1 & 4.3 & 3.1 & 1.7 & 0.98 & 1.05 & 1.13 & 1.27 & 1.26 \\
\hline $2000 \mathrm{~h}$ & 220 & 223 & 225 & 232 & 230 & 1.4 & 1.3 & 1.4 & 2.3 & 2.0 & 1.33 & 1.20 & 1.17 & 1.29 & 1.26 \\
\hline
\end{tabular}

Use of the ZQ97 adsorption isotherm produced nearly identical behavior of air- $e$ as J97 at Phoenix, as stated above, but the ground-adsorbed amounts then are much smaller, about $0.15 \mathrm{~kg} \mathrm{~m}^{-3}$ at 1400 LTST, $0.30 \mathrm{~kg} \mathrm{~m}^{-3}$ at 0200 LTST at the surface, and about $0.25 \mathrm{~kg} \mathrm{~m}^{-3}$ at the $3.8 \mathrm{~cm}$ depth. These values are also consistently about threefold to those obtained with the use of ZQ97 at the MSL site in Steele et al. (2017). 


\section{Conclusions}

We have compared two recalibrations of the Phoenix TECP air humidity measurements to each other and to results from simulations with a subsurface-atmosphere single column model having a diurnal soil adsorption/desorption cycle based on the Jakosky et al. (1997, J97) adsorption isotherm. Comparison was made here for a clear-sky warm midsummer period (sols 50-60, $\mathrm{L}_{\mathrm{s}} 98^{\circ}-103^{\circ}$ ) at Phoenix, when there were enough observations to define the full diurnal moisture cycle without complicating water vapor condensation effects (i.e. no fog and no strong frosts). The observed MET-mast temperature range was 192-244K at $2 \mathrm{~m}$ height, the model's T2m-range being the same without any bias. The orbit- and SSI-observed precipitable water content of the air was about $30 \mu \mathrm{m}$ during the period. The model was initialized to that value using a linear GCM-indicated profile for the water vapor mass mixing ratio.

During sols 54-55 the TECP device was on the ground, with air intake for its relative humidity sensor (on the electricity board) being at $3 \mathrm{~cm}$ height, i.e. near the surface. During the other sols the intake was at $48-111 \mathrm{~cm}$ heights, i.e. in the air. The readings of $\mathrm{RH}$ and board temperature were later recalibrated to the respective air frost points by Zent et al. (2016; Z), and by the University of Michigan group (Fischer et al., 2019; F). From these the water vapor partial pressure $e$ at the sensor height and ambient $\mathrm{RH}$ at $2 \mathrm{~m}$ height $\left(\mathrm{RH} 2 \mathrm{~m} \sim e / e_{\text {sat }}(\mathrm{T} 2 \mathrm{~m})\right)$ could be extracted and compared to model predictions.

The values for RH2m are quite low during the day $(1-8 \%$ by the $\mathrm{F}$ recalibration and $0.1-0.8 \%$ by the $\mathrm{Z}$ recalibration), whereas during the coldest hour of 0200 LTST, RH $2 \mathrm{~m}$ is close to $100 \%$ by the $\mathrm{Z}$ recalibration and around $60 \%$ by the $F$ recalibration. Fog was not reported for this period, but very light frost may have occurred occasionally. The model-indicated RH2m is closer to the Z recalibration during the night but to the $\mathrm{F}$ recalibration during the morning, midday and evening (Fig. 2). On the other hand the model's surface-e is slightly closer to the F-recalibrated near-surface $e$ at night (Fig. 3). We conclude, as Fischer et al. (2019), that during nighttime the F recalibration is in fair agreement with the $\mathrm{Z}$ recalibration and the model simulation is close to both of them, so both recalibrations have (different) merits during nighttime. Instead, during daytime the model results are much closer to the F-recalibrated $\mathrm{RH} 2 \mathrm{~m}$ and $e$, agreeing with the daytime SSI and CRISM observations of column water. Hence the F-recalibration is recommended for daytime values.

The recalibrations and the model suggest low values of $e(0.03-0.04 \mathrm{~Pa})$ at nighttime, with a rapid increase in the morning to around 0.4-0.6 Pa during daytime at 0.48-1.11 $\mathrm{m}$ heights, and even higher very near the sun-heated midday surface by the $\mathrm{F}$ recalibration and by the model. After about 1800 LTST air moisture then begins to decrease rapidly, especially near the surface. The depletion is due to downward turbulent diffusion and subsequent adsorption onto regolith grains in the model, the daily desorbed and adsorbed water being in a reversible, approximately PWC-conserving balance for regolith porosity of $16 \%$. The depleted layer of air moisture extends to only about 200 $\mathrm{m}$ in the model; hence PWC stays around the observed $30 \mu \mathrm{m}$ throughout the sol, with only $\sim 1 \%$ diurnal variation due to the adsorption/desorption cycle.

Sensitivity experiments with the model indicate that the best agreement with the F-recalibrated water vapor pressure cycle was obtained via using the observed PWC of $30 \mu \mathrm{m}$ and a low regolith porosity $f$ of $16 \%$, consistent with the observed crust in the topsoil around the Phoenix site (Smith et al., 2009). The results show little sensitivity to the exact value of tortuosity as long as this is made somehow inversely proportional to $f$. Low constant value for the molecular/Knudsen diffusion coefficient $D$, e.g. the much-used $1 \mathrm{~cm}^{2} / \mathrm{s}$, leads to too weak evening adsorption and hence to too early and too strong frost formation in the experiments, $D$ and $D_{e}$ of $5 \mathrm{~cm}^{2} / \mathrm{s}$ appearing to be a more 
useful constant value. If adsorption is fully shortcut in the model, the remaining diffusion of water vapor in the soil is weak and this, too, leads to strong night frosts. Strong frosts were not observed during the warm period.

Higher (lower) $f$ than $16 \%$ increased (decreased) adsorption too much and indicated rapid unobserved growth (decay) of PWC from sol to sol during the simulation, as did use of the Fanale and Cannon (1971) adsorption isotherm. On the other hand adopting the Zent and Quinn (1997) adsorption isotherm led to air results, which are nearly identical with those using the J97 isotherm, but the nocturnally adsorbed soil water amounts then are much smaller. This suggests that more laboratory determinations of adsorption in Mars-like conditions, future soil sample returns or in-situ martian soil moisture measurements would be helpful to advantage our understanding of this peculiar phenomenon.

Acknowledgements: LPI Contribution No. $x x x x$. LPI is operated by USRA under a cooperative agreement with the Science Mission Directorate of the National Aeronautics and Space Administration. The work was supported by the Academy of Finland grants 131723, 132825 and 310509. G. M. Martínez and E. Fischer wish to acknowledge NASA Mars Data Analysis Program Award \#14-MDAP14_2-0113, which funded efforts to obtain the new PHX/TECP relative humidity data used in this work. We thank the reviewers for their excellent comments.

\section{References:}

Boynton WV et al., 2009. Evidence for calcium carbonate at the Mars Phoenix landing site. Science 325 (5936), 61-64. doi:10.1126/science.1172768

Davy R, Davis JA, Taylor PA, Lange CF, Weng W, Whiteway JA, Gunnlaugson HP, 2010. Initial analysis of air temperature and related data from the Phoenix MET station and their use in estimating turbulent heat fluxes, J. Geophys. Res. 115, E00E13, doi:10.1029/2009JE003444.

Fanale FP, Cannon WA, 1971: Adsorption on the Martian regolith. Nature 230, 502-504.

Fischer E, Martinez GM, Elliott HM, Renno NO, 2014. Experimental evidence for deliquescence on Mars. Geophys. Res. Lett. 41, doi:10.1002/2014GL060302.

Fischer E, Martínez GM, Rennó NO, Tamppari LK, Zent AP, 2019. Relative humidity on Mars: New results from the Phoenix TECP sensor. J. Geophys. Res. (accepted).

Harri A-M et al., 2014. Mars Science Laboratory relative humidity observations: initial results. J. Geoph. Res. Planets 119, 2132-2147, doi: 10.1002/2013JE004514

Hudson TL, Aharonson O, Schorghofer N, Farmer CB, Hecht MH, Bridges NT, 2007. Water vapor diffusion in Mars subsurface environments. J.Geophys.Res. 112, E05016.

Jakosky BM, Zent AP, Zurek RW, 1997. The Mars water cycle: Determining the role of exchange with the regolith. Icarus 130, 87-95.

Martínez GM, et al., 2017. The Modern Near-Surface Martian Climate: A Review of In-situ Meteorological Data from Viking to Curiosity. Space Sci. Rev., pp.1-44.

McConnochie TH et al., 2018. Retrieval of water vapor column abundance and aerosol properties from ChemCam passive sky spectroscopy. Icarus 307, 294-326, doi:10.1016/j.icarus.2017.10.043. 
Meslin P-Y, Adler PM, Sabroux J-C, 2010. Diffusive transport of gases in wet porous media. Application to radon. Soil Sci. Soc. Am. J. 74, 1871-1885.

Montmessin F, Smith MD, Langevin Y, Mellon MT, Fedorova A, 2017. The water cycle, pp 338-373. In "The Atmosphere and Climate of Mars", Haberle RM, Todd Clancy R, Forget F, Smith MD, Zurek RW, eds. Cambridge University Press, 644 pp.

Moores JE, et al., 2011. Observations of near-surface fog at the Phoenix Mars landing site. Geophys. Res. Lett. 38, L04203.

Murphy DM, Koop T, 2005. Review of the vapor pressures of ice and supercooled water for atmospheric applications. Quart. J. Roy. Met. Soc. 131, 1539-1565.

Navarro T et al., 2014. Global climate modeling of the Martian watercycle with improved microphysics and radiatively active water ice clouds. J. Geophys. Res. Planets 119, 1479-1495.

Savijärvi H, Kauhanen J, 2008. Surface and boundary-layer modeling for the Mars Exploration Rover sites. Quart. J. Roy. Met. Soc. 134, 635-641, doi: 10.1002/qj.232

Savijärvi H, Määttänen A, 2010. Boundary-layer simulations for the Mars Phoenix lander site. Quart. J. Roy. Met. Soc. 136, 1497-1505, doi:10.1002/qj.650.

Savijärvi H, Harri A-M, Kemppinen O, 2016. The diurnal water cycle at Curiosity: role of exchange with the regolith. Icarus 265, 63-69, doi:10.1016/j.icarus.2015.10.008.

Savijärvi H, Paton M, Harri A-M, 2018. New column simulations for the Viking landers: winds, fog, frost, adsorption? Icarus 310, 48-53, doi: 10.1016/j.icarus.2017.11.007.

Savijärvi H, McConnochie T, Harri A-M, Paton M, 2019a. Annual and diurnal water vapor cycles at Curiosity from observations and column modeling. Icarus 319, 485-490. doi:10.1016/j.icarus.2018.10.008.

Savijärvi H, McConnochie T, Harri A-M, Paton M, 2019b. Water vapor mixing ratios and air temperatures for three martian years from Curiosity. Icarus 326, 170-175, doi:10.1016/j.icarus.2019.03.020.

Savijärvi H, Martinez G, Harri A-M, Paton M, 2019c. Curiosity observations and column model integrations for a martian global dust event. Icarus, doi:10.1016/j.icarus.2019.113515.

Steele LJ, Balme MR, Lewis SR, Spiga A, 2017. The water cycle and regolith-atmosphere interaction at Gale crater, Mars. Icarus 280, 56-79.

Schorghofer N, Aharonson O, 2005: Stability and exchange of subsurface ice on Mars. J. Geophys. Res. 110, E05003, doi:10.1029/2004JE002350

Sizemore HG, Mellon MT, 2008. Laboratory characterization of the structural properties controlling dynamical gas transport in Mars-analog soils. Icarus 197, 606-620.

Smith PH et al., 2009. $\mathrm{H}_{2} \mathrm{O}$ at the Phoenix landing site. Science 325 (5936), 58-61. doi:10.1126/science.1172339.

Tamppari LK et al., 2010. Phoenix and MRO coordinated atmospheric measurements. J. Geophys.Res. 115, E00E17, doi:10.1029/2009JE003415.

Wallace D, Sagan C, 1979. Evaporation of ice in planetary atmospheres: Ice-covered rivers on Mars. Icarus $39,385-400$.

Whiteway JA et al., 2009. Mars water-ice clouds and precipitation. Science 325 (5936), 68-70. doi:10.1126/science.1172344. 
603

604

605

606

607

608

609

610

611

612

613

614

615

616

617

Zent AP, Haberle RM, Houben HC, Jakosky BM, 1993: A coupled subsurface-boundary layer model of water on Mars. J. Geophys. Res 98, E2, 3319-3337.

Zent AP, Quinn RC, 1997: Measurement of $\mathrm{H}_{2} \mathrm{O}$ adsorption under Mars-like conditions: Effects of adsorbent heterogeneity. J. Geophys. Res 102, E4, 9085-9095.

Zent AP et al., 2009: Thermal and Electrical Conductivity Probe (TECP) for Phoenix. J. Geophys. Res. 114,E00A27, doi:10.1029/2007JE003052.

Zent AP et al., 2010. Initial results from the thermal and electrical conductivity probe (TECP) on Phoenix. J. Geophys. Res. 115, E00E14, doi:10.1029/2009JE003420.

Zent AP, Hecht MH, Hudson TL, Wood SE, Chevrier VF, 2016. A revised calibration function and results for the Phoenix mission TECP relative humidity sensor. J. Geophys. Res. Planets 121, 626-651. 
618

619

620

621

622

623

624

625

626

627

628

629

630

631

632

633

634

635

636

637

638

639

\section{Figures:}

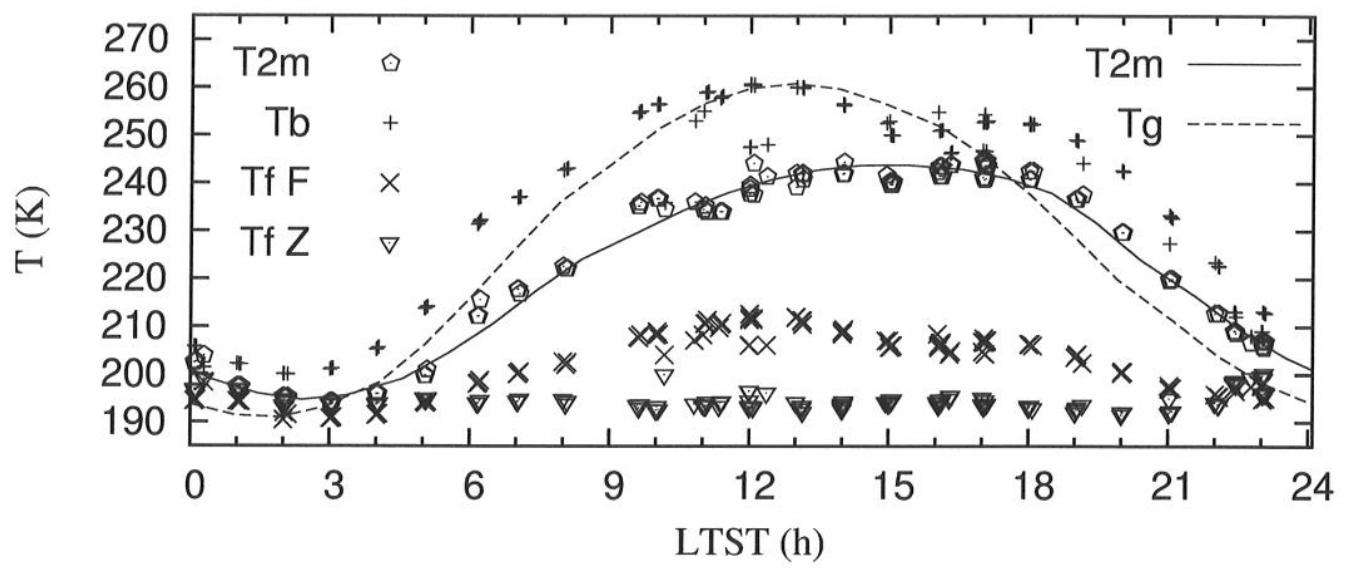

Fig. 1. TECP board temperatures $\left(\mathrm{T}_{\mathrm{b}}\right)$ and frost point temperatures from Fischer et al. $\left(2019, \mathrm{~T}_{\mathrm{f}} \mathrm{F}\right)$ and Zent et al. (2016, $\mathrm{T}_{\mathrm{f}} \mathrm{Z}$ ) for Phoenix lander sols 50-60, together with $2 \mathrm{~m}$ air temperatures from the PHX MET mast (T2m, pentagons) and from the reference sol 55 simulation (T2m, solid line). The model's ground surface temperature is also shown ( $\mathrm{T}_{\mathrm{g}}$, dashed line).

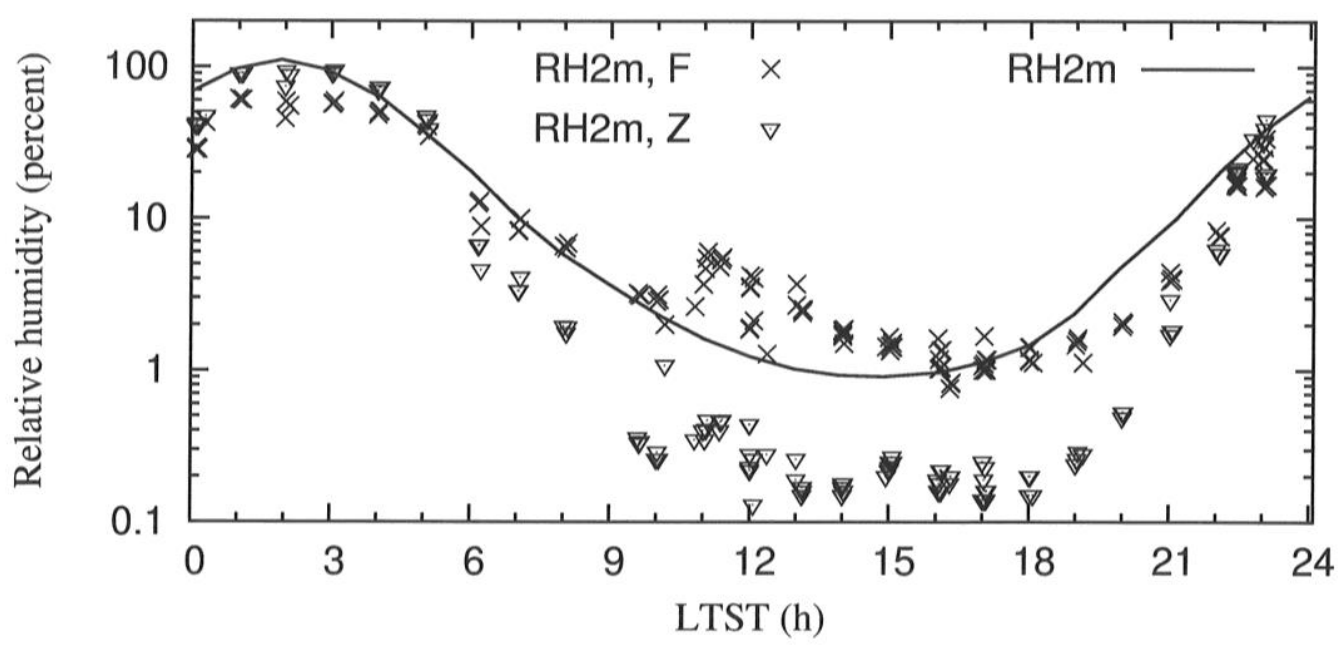

Fig. 2. Relative humidities at $2 \mathrm{~m}$ height from the $\mathrm{F}$ and $\mathrm{Z}$ recalibrations of TECP observations for Phoenix sols 50-60 (see text for details). Note the logarithmic scale. The solid line is RH at $2 \mathrm{~m}$ height from the reference simulation. 


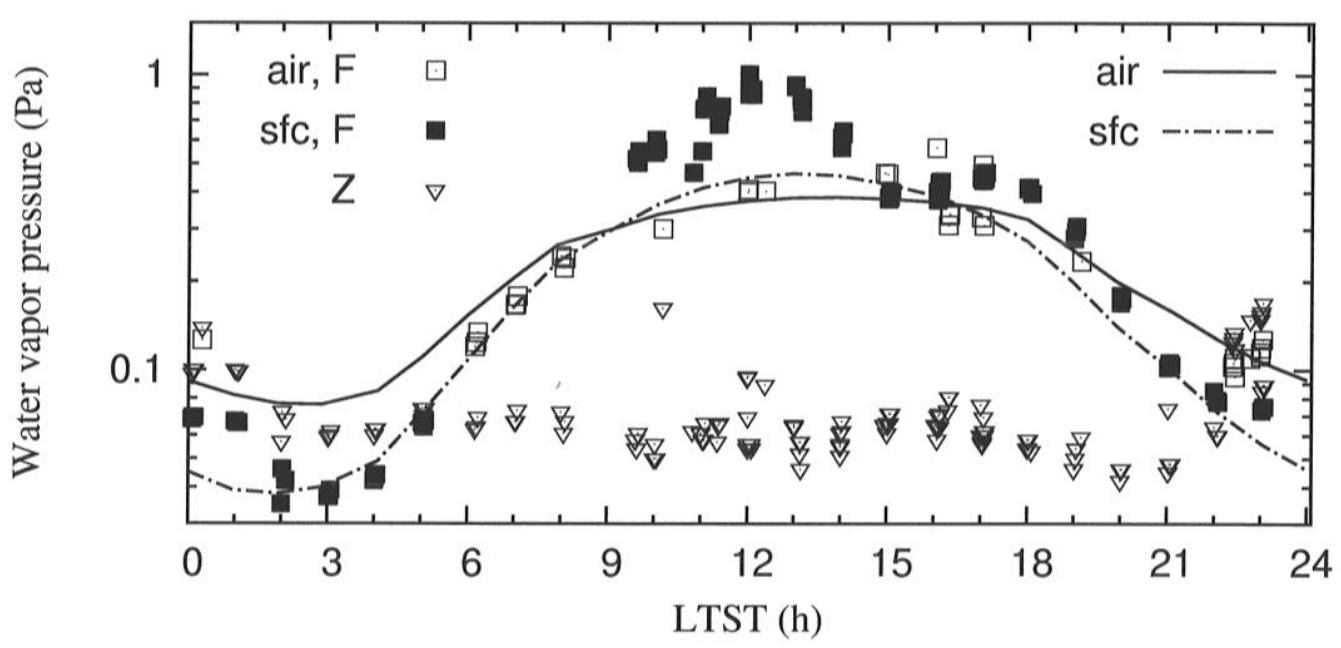

640

641

642

643

644

645

646

647
648

Fig. 3. Water vapor partial pressures $e(\mathrm{~Pa}, \log$ scale) from the $\mathrm{F}$ and $\mathrm{Z}$ recalibrations of TECP air humidity observations for Phoenix sols 50-60. F values of $e$ from 48-111 cm heights (air, F) are open squares; near-surface $e$ from $3 \mathrm{~cm}$ height ( $\mathrm{sfc} \mathrm{F}$ ), black squares. All Z values of $e$ are inverted triangles. Model-e are from $2 \mathrm{~m}$ height (air, solid line) and from the surface (sfc, dash-dotted line).

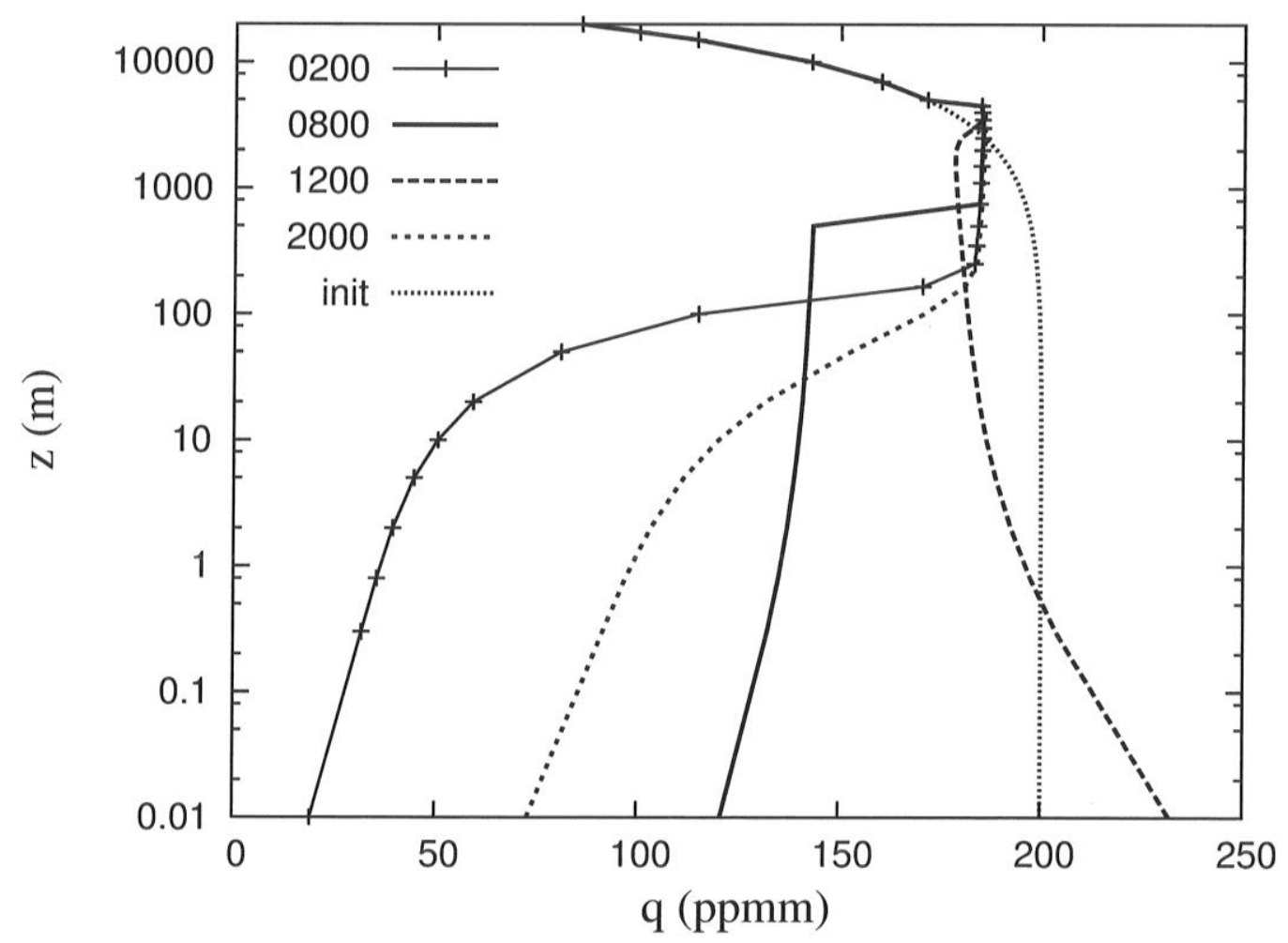

Fig. 4. Model water vapor mass mixing ratio profiles $\mathrm{q}(\mathrm{z})$ from the surface (roughness height of $0.01 \mathrm{~m}$ ) to $20 \mathrm{~km}$ initially (dots) and at 0200, 0800, 1200 and 2000 LTST in the reference simulation. Gridpoint heights are indicated in the 0200 LTST curve. Note growth (by desorption and convection) in the morning and depletion below $200 \mathrm{~m}$ during the evening and night (by downward turbulent diffusion and adsorption onto porous regolith). 
657

658

659

660

661

662

663

664

665

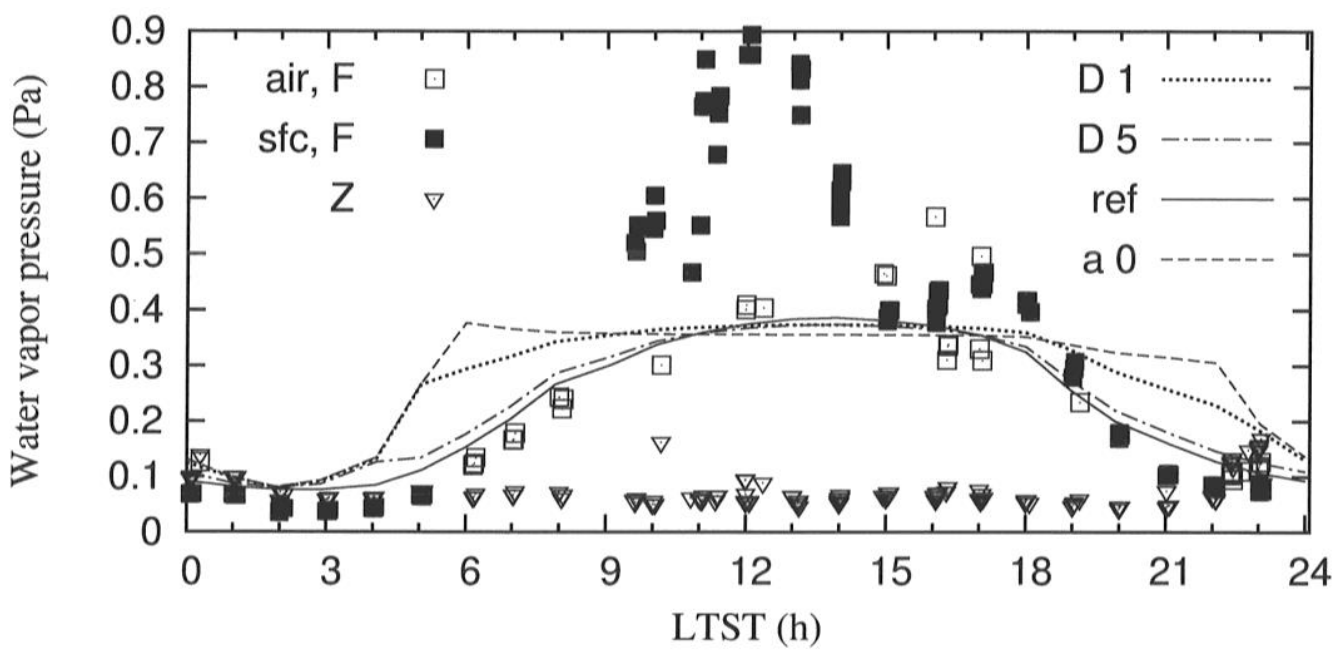

666

667

668

669

670

671

Fig. 5. Water vapor pressures $e$ ( $\mathrm{Pa}$, linear scale) from the two recalibrations $\mathrm{F}$ and $\mathrm{Z}$, and $e$ at $2 \mathrm{~m}$ from model simulations for ground porosities $f$ of $0.05,0.35$ and 0.16 ( $=$ ref, from Fig. 3); and for $f$ of 0.16 but with tortuosity $\tau_{\mathrm{s}}$ of $2.5\left(\mathrm{~T} 2.5, \tau_{\mathrm{s}}=1 / \sqrt{f}\right)$ instead of 6.25 (ref, $\left.\tau_{\mathrm{s}}=1 / f\right)$.

LTST (h)

Fig. 6. Water vapor pressures $e \mathrm{~F}$ and $e \mathrm{Z}$ as in Fig. 5, and $e 2 \mathrm{~m}$ from model simulations for constant $\mathrm{D}$ of 1 and $5 \mathrm{~cm}^{2} / \mathrm{s}$. Shown is also the reference simulation and the reference simulation but without adsorption $(\mathrm{a}=0)$, i.e. with soil diffusion only active.

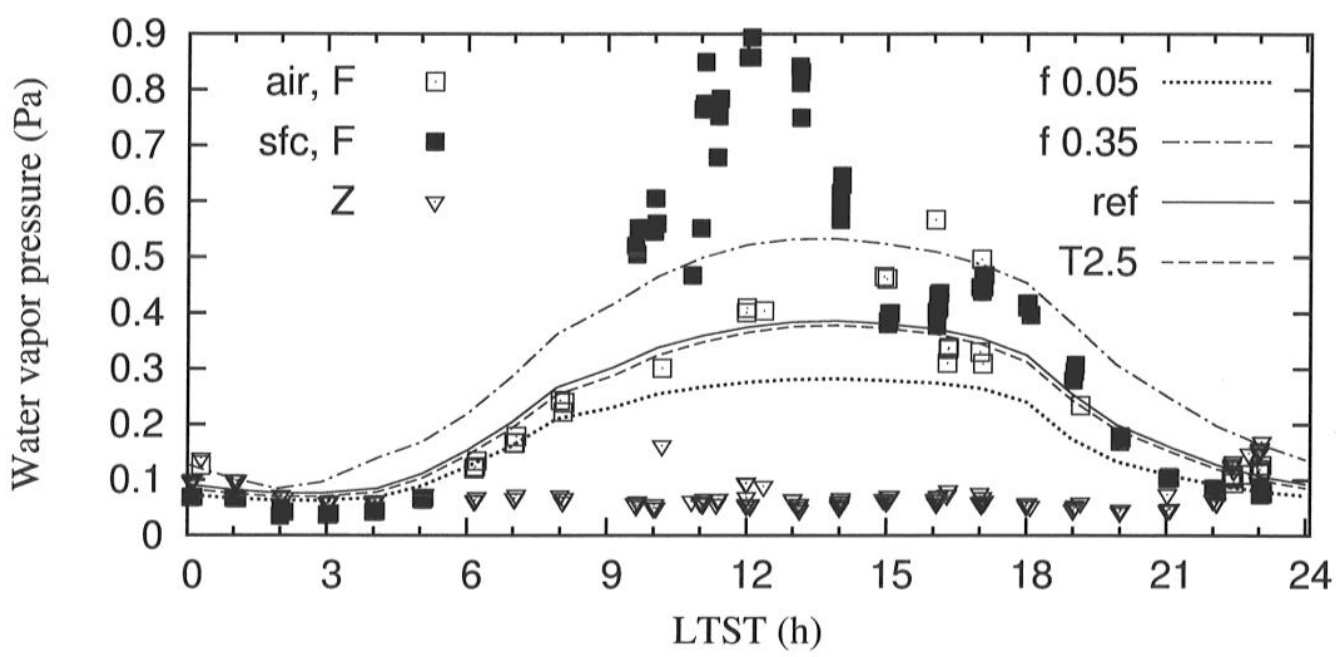


672

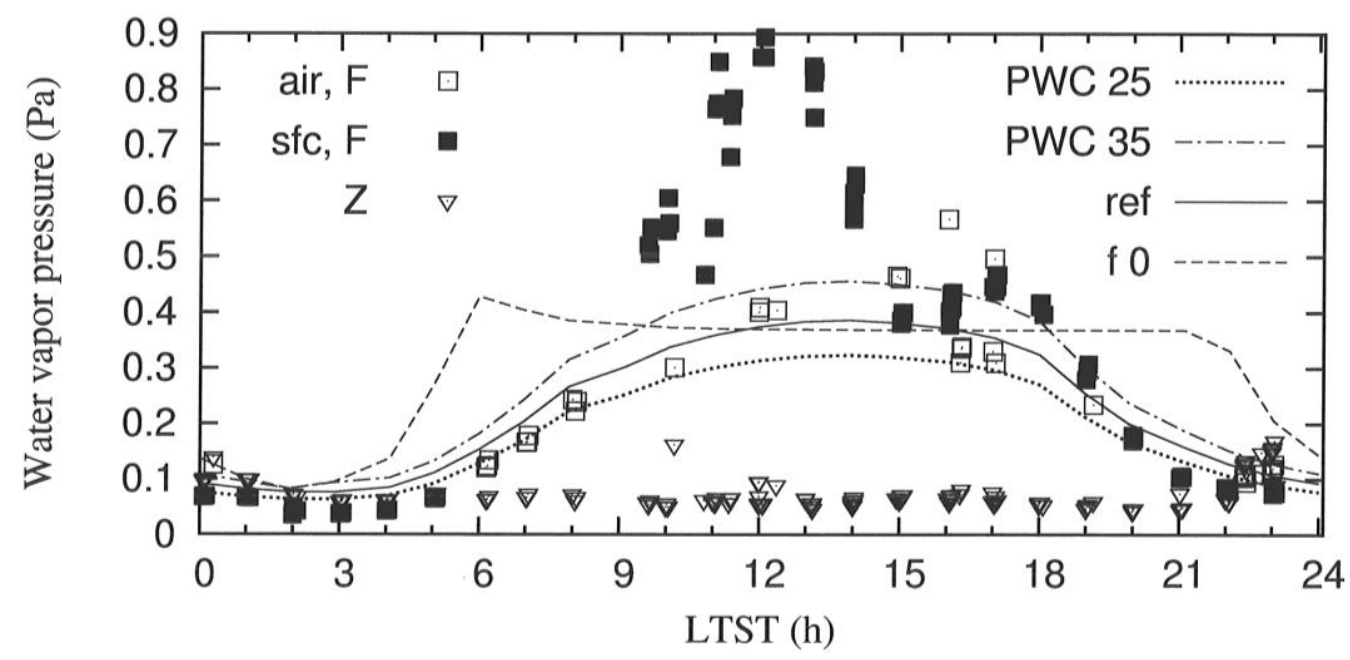

673

674

675

676 677
Fig. 7. Water vapor pressures $e \mathrm{~F}$ and $e \mathrm{Z}$, and $e 2 \mathrm{~m}$ from model simulations with $\mathrm{PWC}$ of 25, 30 (= ref) and $35 \mu \mathrm{m}$. Also shown is the reference simulation but for porosity $f \sim 0$, i.e. solid ground. 